\title{
The heat and mass transfer characteristics of superheated steam in horizontal wells with toe-point injection technique
}

\author{
Fengrui Sun ${ }^{1,2,3} \cdot$ Yuedong $\mathrm{Yao}^{1,2,3} \cdot$ Xiangfang $\mathrm{Li}^{2,3}$
}

Received: 6 July 2017 / Accepted: 26 November 2017 / Published online: 18 January 2018

(c) The Author(s) 2018. This article is an open access publication

\begin{abstract}
Little efforts were done on the heat and mass transfer characteristics of superheated steam (SHS) flow in the horizontal wellbores. In this paper, a novel numerical model is presented to analyze the heat and mass transfer characteristics of SHS in horizontal wellbores with toe-point injection technique. Firstly, with consideration of heat exchange between inner tubing (IT) and annuli, a pipe flow model of SHS flow in IT and annuli is developed with energy and momentum balance equations. Secondly, coupled with the transient heat transfer model in oil layer, a comprehensive mathematical model for predicting distributions of pressure and temperature of SHS in IT and annuli is established. Then, type curves are obtained with numerical methods and iteration technique, and sensitivity analysis is conducted. The results show that (1). The decrease in SHS temperature in annuli caused by heat and mass transfer to oil layer is offset by heat absorbtion from SHS in IT. (2). SHS temperature in both IT and annuli increases with the increase in injection pressure. (3). IT heat loss rate decreases with the increases in injection pressure. (4). Increasing pressure can improve development effect.
\end{abstract}

Keywords Superheated steam injection · Toe-point injection technique $\cdot$ Horizontal wellbores · Distributions of pressure and temperature $\cdot$ Heavy oil recovery

\section{List of symbols \\ $A_{\mathrm{d}} \quad$ The oil drainage area of the discrete horizontal segment $\left(\mathrm{m}^{2}\right)$ \\ $B_{\mathrm{o}} \quad$ The volume coefficient of oil $\left(\mathrm{m}^{3} / \mathrm{m}^{3}\right)$ \\ $B_{\mathrm{w}} \quad$ The volume coefficient of water $\left(\mathrm{m}^{3} / \mathrm{m}^{3}\right)$ \\ $f_{\text {perf }}$ The friction factor of perforation roughness (dimensionless) \\ $g \quad$ Gravity acceleration $\left(\mathrm{m} / \mathrm{s}^{2}\right)$ \\ $h_{\mathrm{IT}} \quad$ SHS enthalpy in IT $(\mathrm{J} / \mathrm{kg})$ \\ $h_{\mathrm{an}} \quad$ SHS enthalpy in annuli $(\mathrm{J} / \mathrm{kg})$}

Fengrui Sun

13126682711@163.com

Yuedong Yao

yaoyuedong@163.com

1 State Key Laboratory of Petroleum Resources and Prospecting, China University of Petroleum - Beijing, Beijing 102249, People's Republic of China

2 College of Petroleum Engineering, China University of Petroleum - Beijing, Beijing 102249, People's Republic of China

3 Laboratory for Petroleum Engineering of the Ministry of Education, China University of Petroleum - Beijing, Beijing 102249, People's Republic of China $h_{\text {fITi }} \quad$ Forced convection heat transfer coefficient on inside wall of the IT $\left(\mathrm{W} / \mathrm{m}^{2} \mathrm{~K}\right)$

$h_{\text {fITo }} \quad$ Forced convection heat transfer coefficient on outside wall of the IT $\left(\mathrm{W} / \mathrm{m}^{2} \mathrm{~K}\right)$

$I_{\text {an }} \quad$ Volume flow velocity of SHS from annuli to oil layer $\left(\mathrm{m}^{3} / \mathrm{s}\right)$

$I_{\mathrm{r}} \quad$ The injection production ratio (dimensionless)

$J_{\text {an }} \quad$ The production index $\left(\mathrm{m}^{3} / \mathrm{s} \mathrm{Pa}\right)$

$K_{\mathrm{h}} \quad$ The horizontal permeability of the reservoir (D)

$K_{\mathrm{v}} \quad$ The vertical permeability of the reservoir (D)

$K_{\text {ro }} \quad$ The relative permeability of oil (dimensionless)

$K_{\mathrm{rw}} \quad$ The relative permeability of water (dimensionless)

$L \quad$ Distance to the heel point (m)

$N_{R e} \quad$ The Reynolds number (dimensionless)

$p_{\text {IT }} \quad$ SHS pressure in IT $(\mathrm{Pa})$

$p_{\text {an }} \quad$ SHS pressure in annuli $(\mathrm{Pa})$

$p_{\mathrm{r}} \quad$ The reservoir pressure $(\mathrm{Pa})$

$Q_{\text {IT }} \quad$ The heat exchange rate between IT and annuli (W)

$Q_{\text {an }} \quad$ Heat loss rate from annuli to oil layer (W)

$r_{\text {ITi }} \quad$ The inner radius of IT $(\mathrm{m})$

$r_{\text {ITo }} \quad$ The outer radius of IT (m)

$r_{\mathrm{wi}} \quad$ Inner radius of the wellbore (m)

$S \quad$ The skin factor (dimensionless)

$T_{\text {IT }} \quad$ SHS temperature in IT (K)

$T_{\text {an }} \quad$ SHS temperature in annuli (K) 
$T_{\text {ei }} \quad$ Reservoir temperature (K)

$U_{\text {ITo }} \quad$ Comprehensive heat transfer coefficient between IT and annuli ( $\left.\mathrm{W} / \mathrm{m}^{2} \mathrm{~K}\right)$

$v_{\text {IT }} \quad$ The flow velocity of SHS in IT $(\mathrm{m} / \mathrm{s})$

$v_{\mathrm{r}} \quad$ Radial injection rate $(\mathrm{m} / \mathrm{s})$

$v_{\text {IT }}$ The flow velocity of SHS in annuli $(\mathrm{m} / \mathrm{s})$

$w_{\text {IT }} \quad$ Mass flow rate in IT $(\mathrm{kg} / \mathrm{s})$

$w_{\text {an }} \quad$ Mass flow rate in annuli $(\mathrm{kg} / \mathrm{s})$

\section{Greek letters}

$\beta \quad$ The unit conversion factor (dimensionless)

$\rho_{\text {IT }} \quad$ SHS density in IT $\left(\mathrm{kg} / \mathrm{m}^{3}\right)$

$\rho_{a n} \quad$ SHS density in annuli $\left(\mathrm{kg} / \mathrm{m}^{3}\right)$

$\theta \quad$ Well angle from horizontal (rad)

$\tau_{\mathrm{f}} \quad$ Shear stress in IT (N)

$\lambda_{\text {IT }}$ Thermal conductivity of IT (W/m K)

$\lambda_{\mathrm{e}} \quad$ The reservoir thermal conductivity $(\mathrm{W} / \mathrm{m} \mathrm{K})$

$\mu_{\mathrm{o}} \quad$ Oil viscosity (Pa s)

$\mu_{\mathrm{w}} \quad$ Water viscosity ( $\left.\mathrm{Pa} \mathrm{s}\right)$

$\mu_{\mathrm{IT}, \text { an }}$ SHS viscosity in IT and annuli (Pa s)

$\Delta \quad$ The relative roughness (dimensionless)

\section{Introduction}

Steam injection is one of the most effective methods for heavy oil recovery (Sun et al. 2017a, b, c). When steam is injected from ground to oil layer, one of the foremost tasks for engineers is to predict the distributions of pressure and temperature along the wellbores (Sun et al. 2017d, e). However, the predicting task is never easy due to the complexity of the non-isothermal flow characteristics of thermal fluid in wellbores (Sun et al. 2017f, g).

Willhite (1967) developed an important model for calculating overall heat transfer coefficient during the steam injection process. Ejiogu and Fiori (1987) and Tortike and Farouq Ali (1989) presented empirical formulas for calculating steam thermophysical properties. Sagar et al. (1991) proposed a simplified model for predicting temperature distribution of saturated steam along the vertical wellbores based on the Coulter-Bardon equation, and Alves et al. (1992) developed a new model describing the relationships between enthalpy and pressure in wellbores. Bahonar et al. $(2010,2011)$ took vertical heat transfer into consideration and proposed their numerical model which was later compared with previous models.

Satter et al. (1965) presented a mathematical model for predicting steam quality. However, they ignored the kinetic energy change in their energy balance equation. Pacheco et al. (1972) developed an improved model with consideration of friction losses. Farouq Ali (1981) presented a model that can be used to predict steam pressure and temperature for both downward and upward flow in the vertical wellbores. Durrant and Thambynayagam (1986) proposed another method for calculating transient thermal conductivity with superposition method. Based on previous works, Livescu et al. (2010a, b) proposed a semi-analytical model for predicting multiphase flow pressure and temperature. Hasan (1995), Hasan and Kabir (1991, 1992, 1994, 2007, 2009, 2010, 2012) and Hasan et al. (2007a, b) did a series of works on the steady-state heat conduction rate and transient heat conduction rate in the formation. Cheng et al. (2011, 2012, 2013, 2014) presented several models for predicting heat loss rate in the formation. All of these great works laid a solid foundation for later study. However, they were focused on saturated steam, which is not applicable for superheated conditions.

In recent years, Zhou et al. (2010), Xu et al. (2013a, b), Fan et al. (2016) and Sun et al. (2017h, i) developed different models to predict the distributions of pressure and temperature of SHS in the vertical wellbores. However, it is a constant mass flow process in the vertical wellbores. Dong et al. $(2014,2016)$ proposed a numerical model for predicting steam pressure in the horizontal wellbores. However, it is conventional heel-point steam injection technique, and they focused on the flow characteristics of multi-component thermal fluid. Gu et al. (2015) proposed a numerical model for predicting superheated steam pressure along the horizontal wellbores. Besides, it is also focused on the heel-point steam injection technique.

It is proved by field practices that conventional heelpoint steam injection technique may lead to serious fingering phenomenon (Sun et al. 2018a; Wu et al. 2012). Consequently, the alternative steam injection technique was proposed to overcome these shortcomings (Sun et al. 2018a). However, the mass and flow transfer characteristics of SNG in IT and annuli of the horizontal wellbores are quite complex (Sun et al. 2018a).

This paper has mainly three contributions to the existing body of the literature: (1). A novel model is developed to predict SHS pressure and temperature along the horizontal wellbores with toe-point SHS injection technique. (2). Effect of SHS flow in IT on the profiles of SHS pressure and temperature in annuli is taken into consideration. (3). Influence of injection pressure on the distributions of SHS pressure and temperature is discussed in detail.

\section{Model description}

\section{General assumptions}

A schematic of SHS flow in toe-point SHS injection wellbores is shown in Fig. 1. In order to establish the model, some basic assumptions are listed below.

(1). Injection parameters of SHS at the heel point of IT are constant. 
(2). Heat flow from SHS in annuli to the outside wall of casing is steady state (Sun et al. 2017j).

(3). Heat flow in oil layer is transient state.

(4). Heat conduction in the horizontal direction is ignored.

\section{Modeling of SHS flow in IT}

It is a constant mass flow process of SHS flow from the heel point to the toe point in IT. The mass balance equation can be expressed as (Sun et al. 2018a):

$\frac{\partial w_{I T}}{\partial L}=\pi r_{I T i}^{2} \frac{\partial\left(\rho_{I T} v_{I T}\right)}{\partial L}=0$

There exists heat exchange between SHS in the IT and annuli (Sun et al. 2018a). The energy balance equation of SHS flow in IT can be given as :

$\frac{\mathrm{d} Q_{I T}}{\mathrm{~d} L}=-w_{I T} \frac{\mathrm{d} h_{I T}}{\mathrm{~d} L}-w_{I T} \frac{\mathrm{d}}{\mathrm{d} L}\left(\frac{v_{I T}^{2}}{2}\right)+w_{I T} g \sin \theta$

The impulse of external force equals the change of SHS momentum (Sun et al. 2018a). The momentum conservation equation can be given as :

$\frac{\mathrm{d} p_{I T}}{\mathrm{~d} L}-\rho_{I T} g \sin \theta+\frac{\tau_{f}}{\pi r_{I T i}^{2} \mathrm{~d} L}+\frac{\mathrm{d}\left(\rho_{I T} v_{I T}^{2}\right)}{\mathrm{d} L}=0$

\section{Modeling of SHS flow in annuli}

It is a variable mass flow process of SHS flow from toe point to heel point in annuli (Sun et al. 2018a). The mass balance equation can be given as:

$w_{a n}=w_{I T}-\int \rho_{a n} I_{a n}$

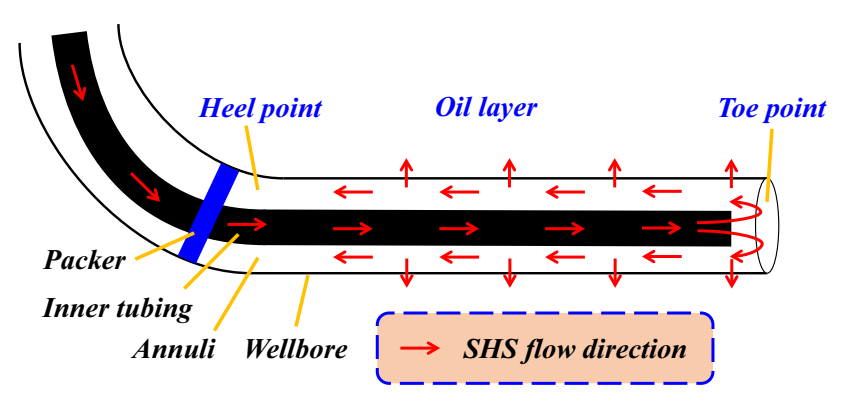

Fig. 1 A schematic of SHS flow in horizontal wellbores with toepoint SHS injection technique
The sum of heat loss from annuli to oil layer and heat conduction from IT to annuli is equal to the total energy change of SHS in annuli (Sun et al. 2018a). The energy balance equation in annuli can be given as:

$$
\begin{aligned}
& \frac{\mathrm{d} Q_{a n}}{\mathrm{~d} L}-\frac{\mathrm{d} Q_{I T}}{\mathrm{~d} L}+\frac{I_{a n} \rho_{a n}\left(h_{a n}+v_{r}^{2} / 2\right)}{\mathrm{d} L} \\
& =-\frac{\mathrm{d}\left(w_{a n} h_{a n}\right)}{\mathrm{d} L}-\frac{\mathrm{d}}{\mathrm{d} L}\left(\frac{w_{a n} v_{a n}^{2}}{2}\right)+w_{a n} g \sin \theta
\end{aligned}
$$

The momentum balance equation of SHS flow in annuli can be given as:

$\frac{\mathrm{d} p_{a n}}{\mathrm{~d} L}=\rho_{a n} g \sin \theta-\frac{\tau_{f}}{\pi r_{w i}^{2} \mathrm{~d} L}-\frac{\mathrm{d}\left(\rho_{a n} v_{a n}^{2}\right)}{\mathrm{d} L}-f_{p e r f} \frac{\rho_{a n} v_{a n}^{2}}{4 r_{w i}}$

\section{Solving method of the mathematical model}

The mathematical model is solved with numerical method. Firstly, Eqs. (2, 3, 5, 6) are converted into different equations, as shown below.

$$
\frac{\Delta Q_{I T}}{\Delta L}=-w_{I T} \frac{\Delta h_{I T}}{\Delta L}-w_{I T} \frac{\Delta}{\Delta L}\left(\frac{v_{I T}^{2}}{2}\right)+w_{I T} g \sin \theta
$$

$\frac{\Delta p_{I T}}{\Delta L}-\rho_{I T} g \sin \theta+\frac{\tau_{f}}{\pi r_{I T i}^{2} d L}+\frac{\Delta\left(\rho_{I T} v_{I T}^{2}\right)}{\Delta L}=0$

$\frac{\Delta Q_{a n}}{\Delta L}-\frac{\Delta Q_{I T}}{\Delta L}+I_{a n} \frac{\Delta \rho_{a n}\left(h_{a n}+v_{r}^{2} / 2\right)}{\Delta L}$

$=-\frac{\Delta\left(w_{a n} h_{a n}\right)}{\Delta L}-\frac{\Delta}{\Delta L}\left(\frac{w_{a n} v_{a n}^{2}}{2}\right)+\Delta w_{a n} g \sin \theta$

$\frac{\Delta p_{a n}}{\Delta L}=\Delta \rho_{a n} g \sin \theta-\frac{\tau_{f}}{\pi r_{w i}^{2} d L}-\frac{\Delta\left(\rho_{a n} v_{a n}^{2}\right)}{\Delta L}-f_{p e r f} \frac{\Delta \rho_{a n} v_{a n}^{2}}{4 r_{w i}}$

Then, the pressure and temperature of SHS in IT and annuli at the outlet of $m$ th segment are obtained by iteration technique. Finally, these outlet results are input as inlet values of the $(m+1)$ th segment, and the distributions of pressure and temperature in IT and annuli are obtained from toe point to heel point. 


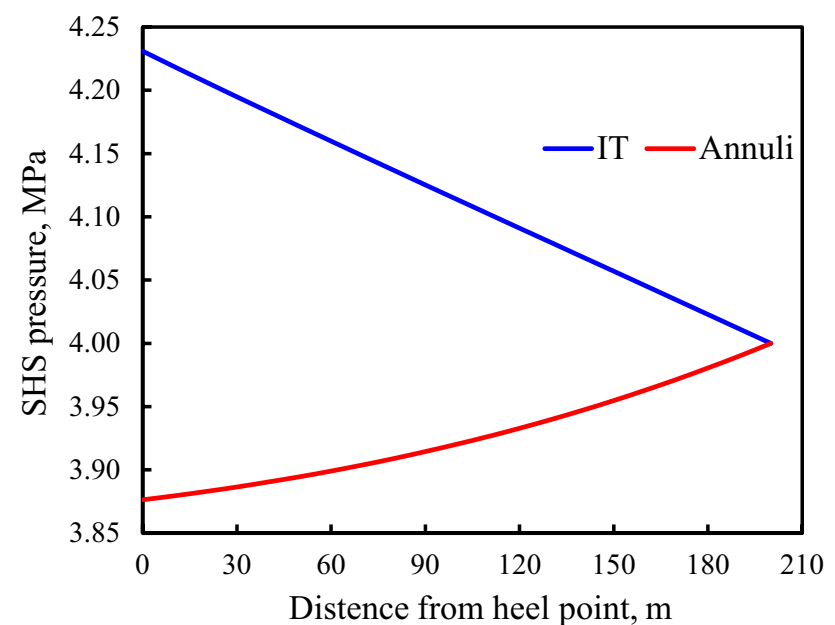

Fig. 2 Predicted SHS pressure in IT and annuli

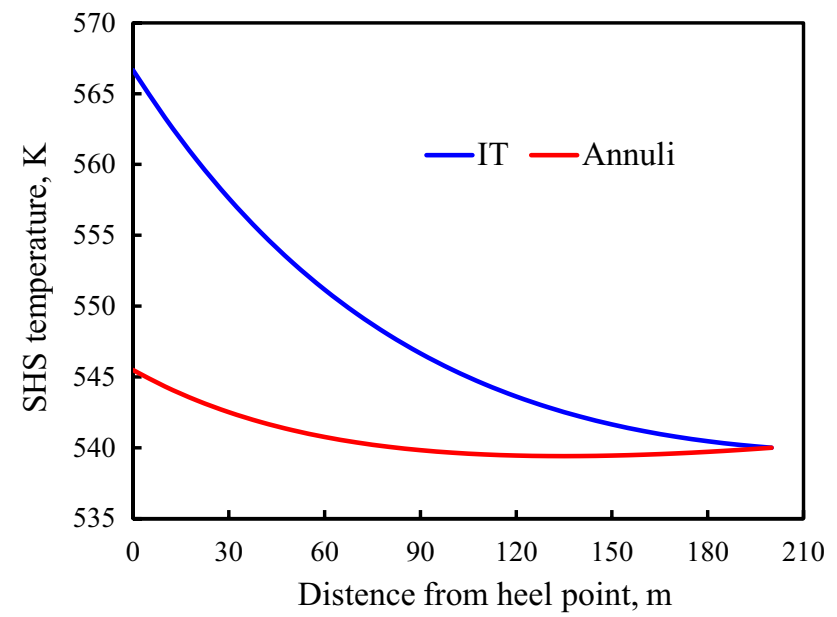

Fig. 3 Predicted SHS temperature in IT and annuli

\section{Results and discussion}

\section{Type curve analysis}

In this section, type curves of SHS flow in IT and annuli are obtained and discussed in detail (Huang et al. 2017, 2018a, 2018b; Feng et al. 2018; Sun et al. 2017k, 2017l, 2018b; Zhang et al. 2017a, 2017b; Chen et al. 2015, 2016, 2017). The injection pressure, temperature and mass flow rate at the heel point are $4.231 \mathrm{MPa}, 566.6 \mathrm{~K}$ and $3 \mathrm{~kg} / \mathrm{s}$, respectively. The predicted results are shown in Figs. 2, 3, 4, 5 and 6.

As can be seen from Fig. 2, SHS pressure decreases with the increase in distance from heel point. As shown in Fig. 3, SHS temperature in IT decreases with distance from heel point. However, while there exists heat loss from SHS in annuli to oil layer, SHS temperature in annuli increases

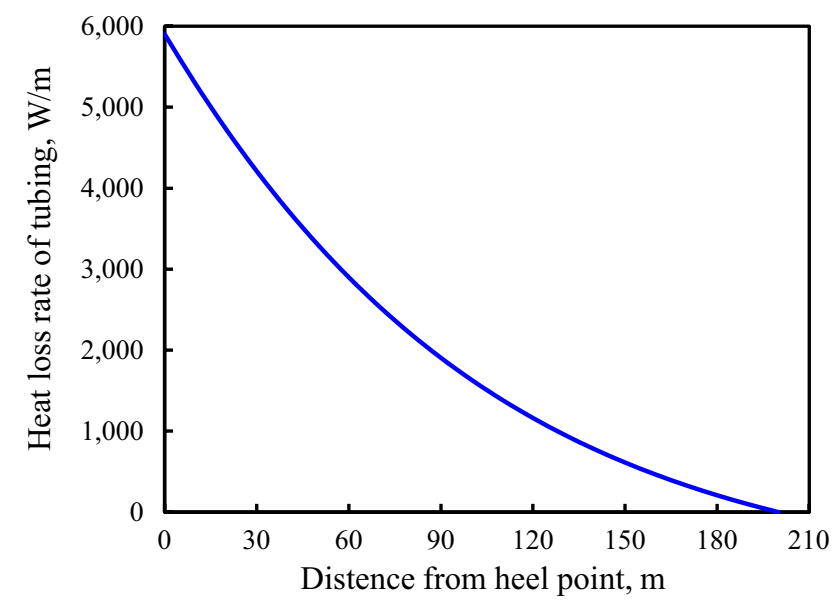

Fig. 4 Predicted heat exchange rate between IT and annuli

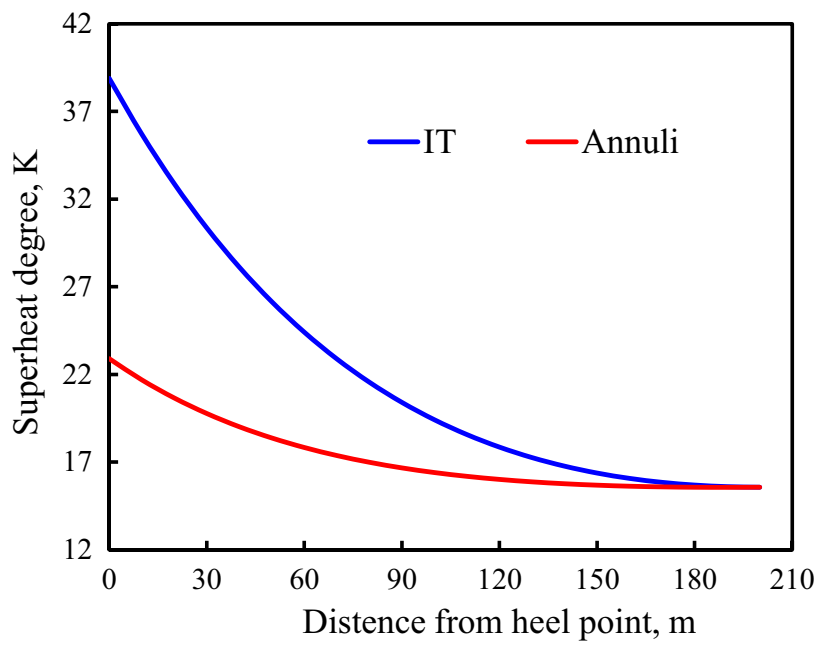

Fig. 5 Predicted superheat degree in IT and annuli

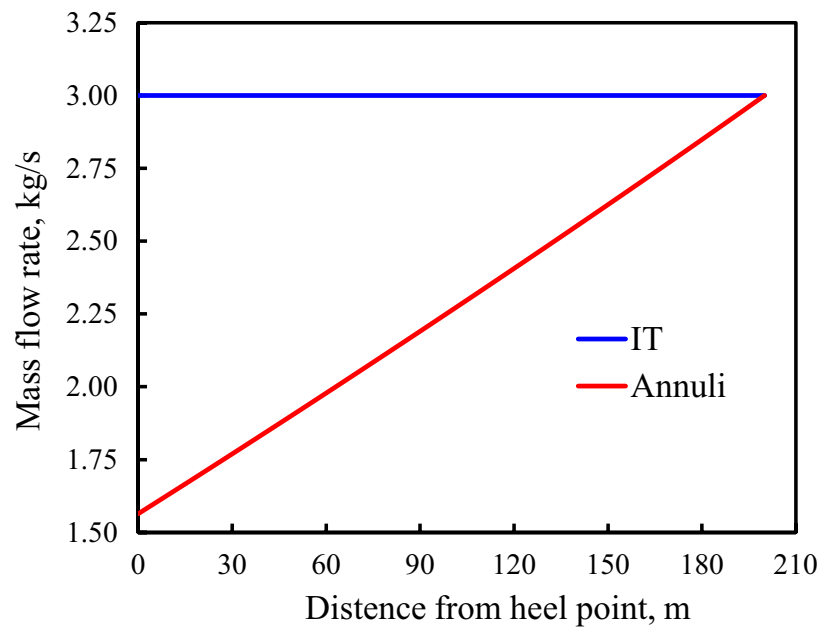

Fig. 6 Predicted mass flow rate in IT and annuli 


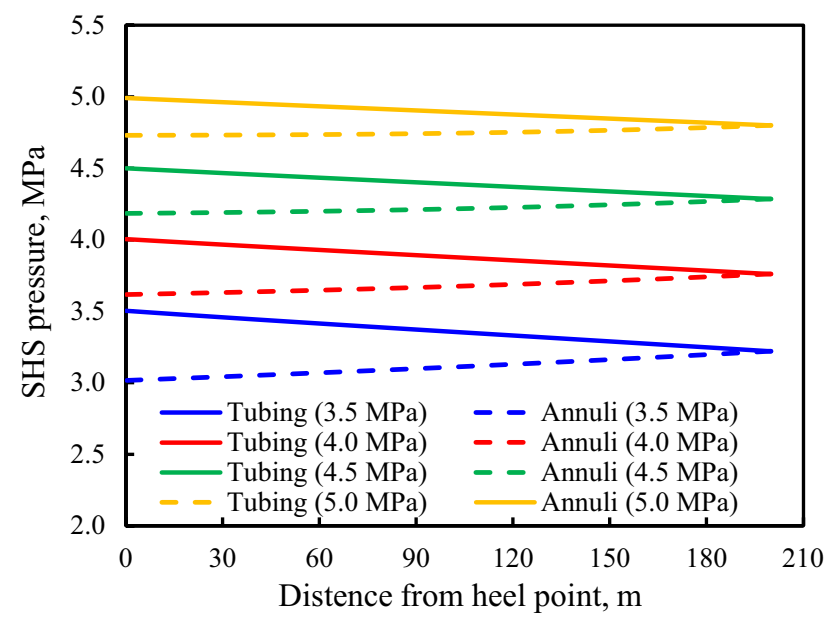

Fig. 7 Effect of injection pressure on the profiles of SHS pressure in IT and annuli

when SHS flows from toe point to heel point. This is because the wellbore heat losses are offset by energy absorbed from IT, as shown in Fig. 4. The heat flow rate from SHS in IT to annuli is obviously higher at the heel point than that at the toe point. Consequently, SHS temperature in annuli has an increase at the heel point. Figure 5 shows the distributions of superheat degree in IT and annuli. It is found that superheat degree decreases when SHS flows from heel point to toe point in annuli, while it increases when SHS flows from toe point to heel point in annuli. This is because the lower-temperature SHS in annuli absorbs huge amount of energy from the higher-temperature SHS in IT. Figure 6 shows clearly that it is a constant mass flow process in IT and it is a variable mass flow in annuli. This is because a certain amount of SHS in annuli is injected into oil layer due to the pressure difference between annuli and oil layer.

\section{Effect of injection pressure}

In order to study the effect of injection pressure on the profiles of thermophysical properties of SHS in wellbores, different injection pressure is tested (3.5, 4.0, 4.5 and 5.0 MPa) based on no change in values of injection rate or temperature. The predicted results under different injection pressure are shown in Figs. 7, 8, 9, 10 and 11.

As can be seen from Fig. 7, SHS pressure in both IT and annuli increases with the increase in injection pressure at heel point in IT. Figure 8 shows that SHS temperature in both IT and annuli increases with the increase in injection pressure. This is because the SHS density increases with the increase in injection pressure, which causes the decrease in flow velocity. And the friction losses decrease accordingly with the decrease in flow velocity, which causes the increase in SHS temperature in IT and annuli.

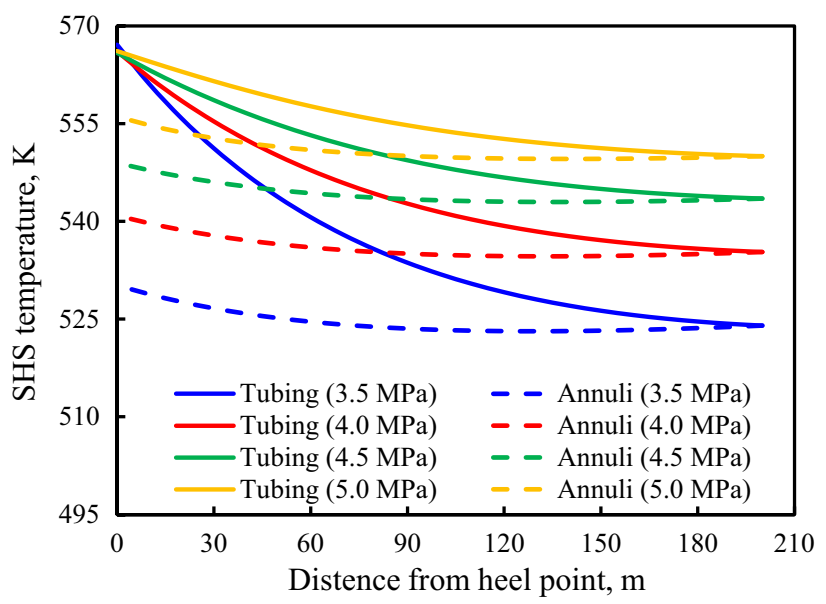

Fig. 8 Effect of injection pressure on the profiles of SHS temperature in IT and annuli

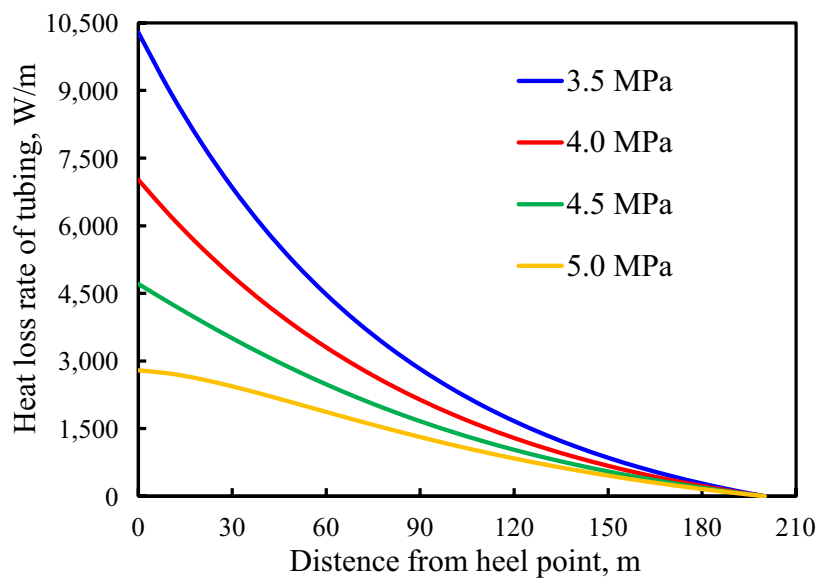

Fig. 9 Effect of injection pressure on the profiles of IT heat loss rate

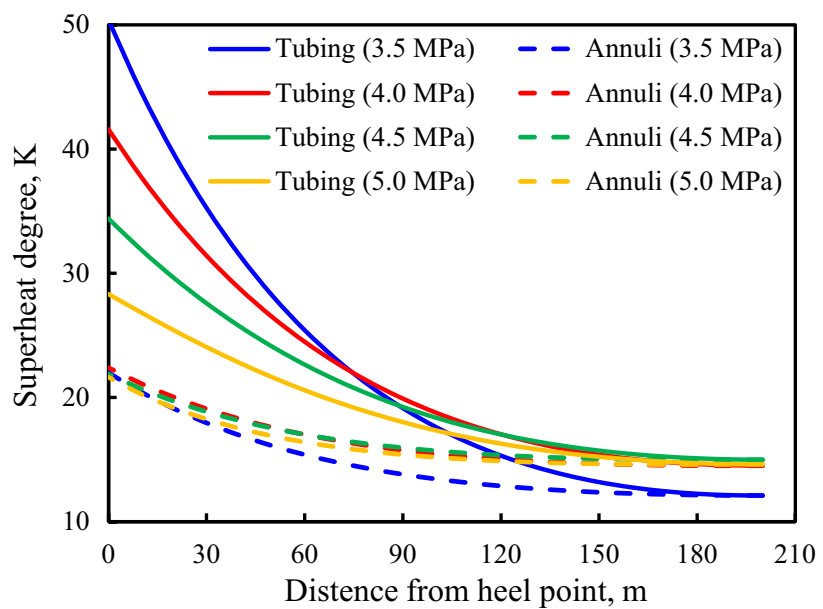

Fig. 10 Effect of injection pressure on the profiles of superheat degree in IT and annuli 


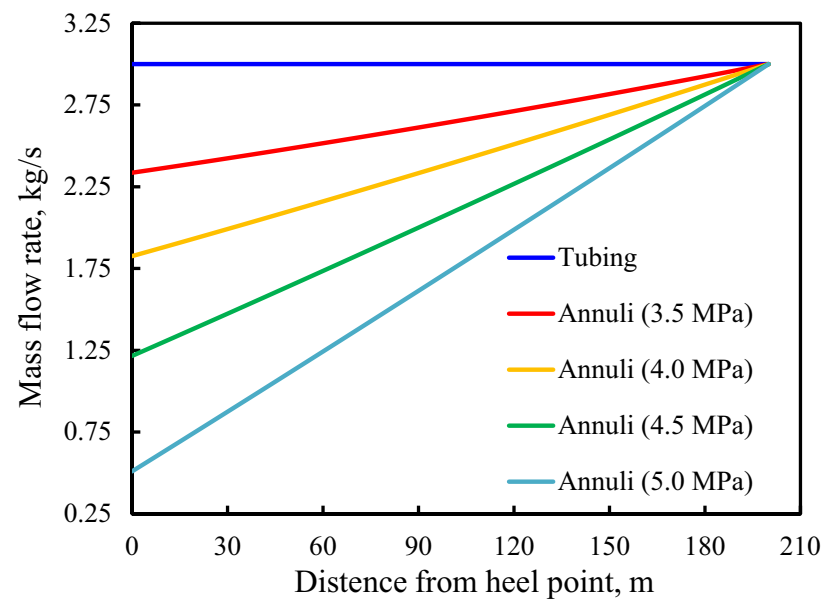

Fig. 11 Effect of injection pressure on the profiles of mass flow rate in IT and annuli

Besides, the temperature difference between IT and annuli decreases with the increases in injection pressure, which causes the decrease in heat exchange rate between IT and annuli, as shown in Fig. 9.

Figure 10 shows that superheat degree in IT decreases with the increase in injection pressure. However, superheat degree in annuli increases slightly with the increase in injection pressure. This means that the injection pressure does little effect on superheat degree of SHS that is injected into oil layer. But the amount of SHS injected into oil layer increases significantly with the increase in injection pressure, as shown in Fig. 11.

\section{Conclusions}

In this paper, a novel numerical model is proposed to analyze the heat and mass transfer characteristics of SHS in horizontal wellbores with toe-point SHS injection technique. Some meaningful findings are listed below.

(1). The decrease in SHS temperature in annuli caused by heat and mass transfer to oil layer is offset by heat absorbtion from SHS in IT.

(2). SHS pressure in both IT and annuli increases with the increase in injection pressure at heel point in IT.

(3). SHS temperature in both IT and annuli increases with the increase in injection pressure.

(4). The temperature difference between IT and annuli decreases with the increase in injection pressure, which causes the decrease in heat exchange rate between IT and annuli.

(5). In order to obtain a satisfactory oil recovery ratio, field engineers are suggested to increase the injection pressure to a reasonable level.
Acknowledgements The authors wish to thank the State Key Laboratory of Offshore Oil Exploitation (2015-YXKJ-001). This work was also supported in part by the National Natural Science Foundation Projects of China (51504269 and 51490654), and the National Science and Technology Major Projects of China (2016ZX05042) and (2017ZX05009-003) to provide research funding.

Open Access This article is distributed under the terms of the Creative Commons Attribution 4.0 International License (http://creativecomm ons.org/licenses/by/4.0/), which permits unrestricted use, distribution, and reproduction in any medium, provided you give appropriate credit to the original author(s) and the source, provide a link to the Creative Commons license, and indicate if changes were made.

\section{Appendix 1: Supplementary materials}

SHS tables used for calculation in this paper can be seen online: http://webbook.nist.gov/chemistry/fluid/.

\section{Appendix 2: Heat exchange rate between IT and annuli}

Based upon previous studies (Sun et al. 2017a; Gu et al. 2014), the heat exchange rate between IT and annuli can be expressed as:

$\frac{\mathrm{d} Q_{I T}}{\mathrm{~d} z}=2 \pi r_{I T o} U_{I T o}\left(T_{I T}-T_{a n}\right)$

where

$U_{I T o}=\left[\frac{r_{I T o}}{\lambda_{I T}} \ln \frac{r_{I T o}}{r_{I T i}}+\frac{r_{I T o}}{h_{f I T i} r_{I T i}}+\frac{1}{h_{f I T o}}\right]^{-1}$

\section{Appendix 3: Volume injection velocity and transient heat transfer rate in oil layer}

Based upon previous works (Dong et al. 2014; Gu et al. 2015; Gu 2016; Chen et al. 2007; Liu 2013), the volume flow velocity can be given as:

$I_{\text {an }}=J_{\text {an }} I_{\mathrm{r}}\left(p_{\text {an }}-p_{\mathrm{r}}\right)$

$J_{\mathrm{an}}=\beta \frac{2 \pi \sqrt{K_{\mathrm{h}} / K_{\mathrm{v}}} K_{\mathrm{v}} \mathrm{d} L\left(K_{\mathrm{ro}} / B_{\mathrm{o}} \mu_{\mathrm{o}}+K_{\mathrm{rw}} / B_{\mathrm{w}} \mu_{\mathrm{w}}\right)}{\ln \frac{0.571 \sqrt{A_{\mathrm{d}}}}{r_{\mathrm{wi}}}+S-0.75}$

$I_{\mathrm{r}}=\frac{2 \ln A_{\mathrm{d}} / r_{\mathrm{wi}}^{2}-3.86}{\ln A_{\mathrm{d}} / r_{\mathrm{wi}}^{2}-2.71}$ 
The heat transfer rate from annuli to oil layer can be expressed as (Liu 2013):

$\frac{\mathrm{d} Q_{\mathrm{an}}}{\mathrm{d} L}=2 \pi \lambda_{\mathrm{e}} \frac{T_{\mathrm{an}}-T_{\mathrm{ei}}}{f(t)}$

where $\lambda_{\mathrm{e}}$ denotes reservoir thermal conductivity, $\mathrm{W} /(\mathrm{m} \mathrm{K})$; $T_{\text {ei }}$ denotes the initial reservoir temperature, $\mathrm{K}$; and $f(t)$ is the function of injection time (Cheng et al. 2012).

\section{Appendix 4: Shear stress in IT and annuli}

In this paper, shear stress is calculated according to Yuan (1982) where it is given as:

$\mathrm{d} \tau_{\mathrm{f}}=\frac{1}{4} \pi r_{\text {wi }} \rho \rho_{\mathrm{IT}, \mathrm{an}} v_{\mathrm{IT}, \mathrm{an}}^{2} \mathrm{~d} L$

where

$$
\begin{cases}f=\frac{64}{N_{\mathrm{Re}}}, & N_{R e} \leq 2000 \\ f=\left[1.14-2 \lg \left(\Delta+21.25 N_{R e}^{-0.9}\right)\right]^{-2}, & N_{R e}>2000\end{cases}
$$

\section{References}

Alves IN, Alhanati FJS, Shoham Ovadia (1992) A unified model for predicting flowing temperature distribution in wellbores and pipelines. SPE Prod Eng 7(4):363-367

Bahonar M, Azaiez J, Chen Z (2010) A semi-unsteady-state wellbore steam/water flow model for prediction of sandface conditions in steam injection wells. J Can Pet Technol 49(9):13-21

Bahonar M, Azaiez J, Chen Z (2011) Two issues in wellbore heat flow modelling along with the prediction of casing temperature in steam injection wells. J Can Pet Technol 59(1):43-63

Chen MD, Zhou JY, Li ZP et al (2007) The model of thermal recovery and steam absorption capacity of horizontal well in heavy oil reservoir. J Southwest Pet Univ Sci Technol 29(4):102-106

Chen Z, Liao X, Zhao X (2015) A new analytical method based on pressure transient analysis to estimate carbon storage capacity of depleted shales: A case study. Int J Greenhouse Gas Control 42:46-58

Chen Z, Liao X, Zhao X, Lv S, Zhu L (2016) A semianalytical approach for obtaining type curves of multiple-fractured horizontal wells with secondary-fracture networks. SPE J 21(02):538-549

Chen Z, Liao X, Zhao X, Dou X, Zhu L, Sanbo L (2017) A finiteconductivity horizontal-well model for pressure-transient analysis in multiple-fractured horizontal wells. SPE J 22(04):1112-1122

Cheng WL, Huang YH, Lu DT et al (2011) A novel analytical transient heat-conduction time function for heat transfer in steam injection wells considering the wellbore heat capacity. Energy 36:4080-4088

Cheng WL, Huang YH, Liu N et al (2012) Estimation of geological formation thermal conductivity by using stochastic approximation method based on well-log temperature data. Energy 38:21-30

Cheng WL, Li TT, Nian YL et al (2013) Studies on geothermal power generation using abandoned oil wells. Energy 59:248-254

Cheng WL, Nian YL, Li TT et al (2014) A novel method for predicting spatial distribution of thermal properties and oil saturation of steam injection well from temperature logs. Energy 66:898-906
Dong XH, Liu HQ, Zhang ZX et al (2014) The flow and heat transfer characteristics of multi-thermal fluid in horizontal wellbore coupled with flow in heavy oil reservoirs. J Pet Sci Eng 122:56-68

Dong XH, Liu HQ, Hou JR, Chen ZX (2016) Transient fluid flow and heat transfer characteristics during co-injection of steam and noncondensable gases in horizontal wells. J China Univ Pet (Ed Nat Sci) 40(2):105-114

Durrant AJ, Thambynayagam RKM (1986) Wellbore heat transmission and pressure drop for steam/water injection and geothermal production: a simple solution technique. SPE Reserv Eng 1(2):148-162

Ejiogu GC, Fiori M (1987) High-pressure saturated steam correlations. J Pet Technol 29(12):1585-1590

Fan ZF, He CG, Xu AZ (2016) Calculation model for on-way parameters of horizontal wellbore in the superheated steam injection. Pet Explor Dev 43(5):798-805

Farouq Ali SM (1981) A comprehensive wellbore steam/water flow model for steam injection and geothermal applications. SPE J 21(5):527-534

Feng D, Li X, Wang X, Li J, Zhang X (2018) Capillary filling under nanoconfinement: The relationship between effective viscosity and water-wall interactions. Int $\mathbf{J}$ Heat Mass Transf 118:900-910

Gu H (2016) Mass and heat transfer model and application of wellbore/formation coupling during steam injection in SAGD process (Doctoral Dissertation). China University of Petroleum, Beijing

Gu H, Cheng LS, Huang SJ, Du BJ, Hu CH (2014) Prediction of thermophysical properties of saturated steam and wellbore heat losses in concentric dual-tubing steam injection wells. Energy 75:419-429

Gu H, Cheng LS, Huang SJ et al (2015) Thermophysical properties estimation and performance analysis of superheated-steam injection in horizontal wells considering phase change. Energy Convers Manag 99:119-131

Hasan AR (1995) Void fraction in bubbly and slug flow in downward vertical and inclined systems. SPE Prod Facil 10(3):172-176

Hasan AR, Kabir CS (1991) Heat transfer during two-phase flow in wellbores: part I-formation temperature. In: Proceedings of the 66th annual technical conference and exhibition, Dallas, TX: SPE22866, pp 469-478

Hasan AR, Kabir CS (1992) Two-phase flow in vertical and inclined annuli. Int J Multiph Flow 18(2):279-293

Hasan AR, Kabir CS (1994) Aspects of wellbore heat transfer during two-phase flow. SPE Prod Facil 9(3):211-216

Hasan AR, Kabir CS (2007) A simple model for annular two-phase flow in wellbores. SPE Prod Oper 22(2):168-175

Hasan AR, Kabir CS (2009) Modeling two-phase fluid and heat flows in geothermal wells. In: Proceedings of the 2009 SPE Western Regional Meeting, San Jose, California, USA: SPE121351, pp $1-13$

Hasan AR, Kabir CS (2010) Sayarpour M. Simplified two-phase flow modeling in wellbores. J Pet Sci Eng 72:42-49

Hasan AR, Kabir CS (2012) Wellbore heat-transfer modeling and applications. J Pet Sci Eng 86-87:127-136

Hasan AR, Kabir CS, Sayarpour M (2007a) A basic approach to wellbore two-phase flow modeling. In: Proceedings of the 2007 SPE annual technical conference and exhibition, Anaheim, California, USA: SPE109868, pp 1-9

Hasan AR, Kabir CS, Wang X (2007b) A robust steady-state model for flowing-fluid temperature in complex wells. In: Proceedings of the 2007 SPE annual technical conference and exhibition, Anaheim, California, USA: SPE109765, pp 1-9

Huang L, Ning Z, Wang Q et al (2017) Thermodynamic and structural characterization of bulk organic matter in chinese silurian shale: experimental and molecular modeling studies. Energy Fuels 31(5):4851-4865

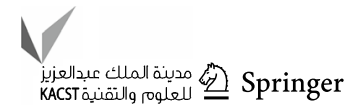


Huang L, Ning Z, Wang Q et al (2018a) Molecular simulation of adsorption behaviors of methane, carbon dioxide and their mixtures on kerogen: Effect of kerogen maturity and moisture content. Fuel 211:159-172

Huang L, Ning Z, Wang Q et al (2018b) Effect of organic type and moisture on $\mathrm{CO}_{2} / \mathrm{CH}_{4}$ competitive adsorption in kerogen with implications for $\mathrm{CO}_{2}$ sequestration and enhanced $\mathrm{CH}_{4}$ recovery. Appl Energy 210:28-43

Liu HQ (2013) Principle and design of thermal oil recovery. Petroleum Industry Press, Beijing

Livescu S, Durlofsky LJ, Aziz K et al (2010a) A fully-coupled thermal multiphase wellbore flow model for use in reservoir simulation. J Pet Sci Eng 71:138-146

Livescu S, Durlofsky LJ, Aziz K (2010b) A semianalytical thermal multiphase wellbore-flow model for use in reservoir simulation. SPE J 15(3):794-804

Pacheco EF, Farouq Ali SM (1972) Wellbore heat losses and pressure drop in steam injection. J Pet Technol 24(2):139-144

Sagar Rajiv, Doty DR, Schmidt Z (1991) Predicting temperature profiles in a flowing well. SPE Prod Eng 6(4):441-448

Satter A (1965) Heat losses during flow of steam down a wellbore. J Pet Technol 17(7):845-851

Sun FR, Yao YD, Li XF, Yu PL, Zhao L, Zhang Y (2017a) A numerical approach for obtaining type curves of superheated multi-component thermal fluid flow in concentric dual-tubing wells. Int J Heat Mass Transf 111:41-53

Sun FR, Li CL, Cheng LS, Huang SJ, Zou M, Sun Q, Wu XJ (2017b) Production performance analysis of heavy oil recovery by cyclic superheated steam stimulation. Energy 121:356-371

Sun FR, Yao YD, Li XF, Zhao L (2017c) Type curve analysis of superheated steam flow in offshore horizontal wells. Int J Heat Mass Transf 113:850-860

Sun FR, Yao YD, Li XF, Zhao L, Ding GY, Zhang XJ (2017d) The mass and heat transfer characteristics of superheated steam coupled with non-condensing gases in perforated horizontal wellbores. J Pet Sci Eng 156:460-467

Sun FR, Yao YD, Li XF, Tian J, Zhu GJ, Chen ZM (2017e) The flow and heat transfer characteristics of superheated steam in concentric dual-tubing wells. Int J Heat Mass Transf 115:1099-1108

Sun FR, Yao YD, Li XF, Li H, Chen G, Sun Z (2017f) A numerical study on the non-isothermal flow characteristics of superheated steam in ground pipelines and vertical wellbores. J Pet Sci Eng 159:68-75

Sun FR, Yao YD, Li XF (2017g) Numerical simulation of superheated steam flow in dual-tubing wells. J Petrol Explor Prod Technol. http s://doi.org/10.1007/s13202-017-0390-7

Sun FR, Yao YD, Li XF, Yu PL, Ding GY, Zou M (2017h) The flow and heat transfer characteristics of superheated steam in offshore wells and analysis of superheated steam performance. Comput Chem Eng 100:80-93

Sun FR, Yao YD, Chen MQ, Li XF, Zhao L, Meng Y, Sun Z, Zhang T, Feng D (2017i) Performance analysis of superheated steam injection for heavy oil recovery and modeling of wellbore heat efficiency. Energy 125:795-804
Sun FR, Yao YD, Li XF (2017j) Effect of gaseous $\mathrm{CO}_{2}$ on superheated steam flow in wells. Eng Sci Technol Int J. https://doi.org/10.1016 /j.jestch.2017.10.003

Sun Z, Li X, Shi J, Yu P, Huang L, Xia J, Sun F, Zhang T, Feng D (2017k) A semi-analytical model for drainage and desorption area expansion during coal-bed methane production. Fuel 204:214-226

Sun Z, Li X, Shi J, Zhang T, Sun F (20171) Apparent permeability model for real gas transport through shale gas reservoirs considering water distribution characteristic. Int J Heat Mass Transf 115:1008-1019

Sun FR, Yao YD, Li XF (2018a) The heat and mass transfer characteristics of superheated steam coupled with non-condensing gases in horizontal wells with multi-point injection technique. Energy 143:995-1005

Sun Z, Li X, Shi J, Zhang T, Feng D, Sun F, Chen Yu, Deng J, Li L (2018b) A semi-analytical model for the relationship between pressure and saturation in the CBM reservoirs. J Nat Gas Sci Eng 49:365-375

Tortike WS, Farouq Ali SM (1989) Saturated-steam-properties functional correlations for fully implicit thermal reservoir simulation. SPE Reserv Eng 40(4):471-474

Willhite GP (1967) Over-all heat transfer coefficients in steam and hot water injection wells. J Pet Technol 19(5):607-615

Wu YB, Li LX, Sun XG, Ma DS, Wang HZ (2012) Key parameters forecast model of injector wellbores during the dual-well SAGD process. Pet Explor Dev 39(4):514-521

Xu AZ, Mu LX, Fan ZF, Wu XH, Zhao L, Bo B et al (2013a) Mechanism of heavy oil recovery by cyclic superheated steam stimulation. J Pet Sci Eng 111:197-207

Xu AZ, Mu LX, Fan ZF, Zhao L (2013b) New findings on heatloss of superheated steam transmitted along the wellbore and heating enhancement in heavy oil reservoirs. In: The international petroleum technology conference held in Beijing, China, 26-28 March 2013

Yuan EX (1982) Engineering fluid mechanics. Petroleum Industry Press, Beijing, pp 87-163

Zhang T, Li X, Sun Z, Feng D, Miao Y, Li P, Zhang Z (2017a) An analytical model for relative permeability in water-wet nanoporous media. Chem Eng Sci 174:1-12

Zhang T, Li X, Li J, Feng D, Li P, Zhang Z, Chen Y, Wang S (2017b) Numerical investigation of the well shut-in and fracture uncertainty on fluid-loss and production performance in gas-shale reservoirs. J Nat Gas Sci Eng 46:421-435

Zhou TY, Cheng LS, He CB, Pang ZX, Zhou FJ (2010) Calculation model of on-way parameters and heating radius in a superheated steam injection wellbore. Pet Explor Dev 37(1):83-88

Publisher's Note Springer Nature remains neutral with regard to jurisdictional claims in published maps and institutional affiliations. 